\title{
STRATEGI PENGEMBANGAN BANJIR KANAL BARAT SEBAGAI DAYA TARIK WISATA DI KOTA SEMARANG
}

\author{
Kismartini, Hendra Kurniawan, Septi Anjani Putri Dwika \\ Departemen Administrasi Publik, Fakultas Ilmu Sosial dan Ilmu Politik, \\ Universitas Diponegoro \\ E-mail: kis_martini@yahoo.co.id
}

\begin{abstract}
The number of tourists visiting Semarang City is increasing significantly year by year. However, this increase is not accompanied by an improvement in the quantity and the quality of tourist destinations in Semarang. Banjir Kanal Barat area is one of the potential tourist destinations in Semarang, but so far the existing facilities in this area are very limited. In addition, there is no any tourism activities which can be done even. Moreover, this area tends to be very unattractive. This study aims to analyze the development strategy of Banjir Kanal Barat (BKB/western canal) as an interesting tourism destination by analyzing internal and external factors. The data were analyzed descriptively qualitative to determine BKB's development strategy through SWOT analysis (Strengths, Weaknesses, Opportunities, and Threats). The results of this study formulated 10 (ten) alternative strategies for the development of Banjir Kanal Barat as a tourism destination area. The three best alternative choices are: (1) creating tourist facilities which can be enjoyed by the community, (2) developing special water attractions, (3) inviting investors and cooperating with various parties.
\end{abstract}

Keywords: development strategy, tourism, SWOT, Banjir Kanal Barat, Semarang

\begin{abstract}
Abstrak
Kunjungan wisatawan di Kota Semarang dari tahun ke tahun semakin meningkat, tapi peningkatan ini tidak disertai dengan meningkatnya kuantitas dan kualitas destinasi wisata. Kawasan Banjir Kanal Barat merupakan salah satu potensi destinasi wisata di kota Semarang, namun sejauh ini fasilitas yang ada di kawasan ini sangat minim, tidak terlihat pula aktivitas wisata yang bisa dilakukan bahkan cenderung tidak menarik. Penelitian ini bertujuan untuk menganalisis strategi pengembangan Banjir Kanal Barat sebagai destinasi wisata yang menarik untuk dikunjungi dengan cara melakukan analisis faktor internal dan eksternal. Data dianalisis secara deskriptif kualitatif untuk menentukan strategi pengembangan BKB melalui analisis SWOT (Strengths/Kekuatan, Weakness/Kelemahan, Opportunities/Peluang, dan Threats/Ancaman). Hasil penelitian ini merumuskan 10 (sepuluh) strategi alternatif bagi pengembangan Banjir Kanal Barat sebagai wilayah destinasi wisata. Tiga alternative pilihan terbaik adalah: (1) menghadirkan fasilitas-fasilitas wisata yang dapat dinikmati oleh masyarakat, (2) mengembangkan atraksi wisata khusus bernuansa air, (3) mengundang investor dan bekerjasama dengan berbagai pihak.
\end{abstract}

Kata Kunci: strategi pengembangan, wisata, SWOT, Banjir Kanal Barat, Semarang 


\section{PENDAHULUAN}

"Pariwisata adalah segala macam kegiatan wisata yang dilayani oleh pemerintah, masyarakat, atau pengusaha beserta dengan fasilitasnya" (UU No.10 Tahun 2009). Pariwisata menjadi sektor strategis karena berhubungan dengan sektor lain secara berkesinambungan. Kepariwisataan merupakan salah satu instrumen peningkatkan kualitas hidup masyarakat, sebagaimana yang ditegaskan oleh Sunaryo (2013: 35).

Mengembangkan pariwisata dibutuhkan perencanaan serta strategi yang mantap untuk mempersiapkan kawasan wisata sebagai daya tarik wisata. Perencanaan dan strategi memungkinkan dipilihnya tindakan-tindakan yang tepat, sesuai dengan situasi dan kondisi. Sebab, strategi dapat mendorong untuk terlebih dahulu membuat perkiraan dan perhitungan mengenai berbagai kemungkinan yang bakal timbul berdasarkan hasil pengamatan dan analisa terhadap situasi dan kondisi yang ada. Strategi yang tepat akan mampu mencapai sasaran-sasaran serta tujuan yang dikehendaki secara maksimal (Shaleh dalam Fatimah, 2015: 20).

Kota Semarang sebagai ibukota provinsi Jawa Tengah adalah sebuah kota transit yang memiliki sejarah panjang dalam peradabannya. Bahkan kota ini dijuluki sebagai "The Little Netherland", hal ini dikarenakan banyaknya sisa-sisa bangunan peninggalan Belanda yang masih tegap berdiri dan berfungsi baik (Kompas, 03 Oktober 2013). Lingkungan sosial dan budaya menjadi nilai jual untuk menjadi salah satu daya tarik wisata. Potensi yang ada, jika terkelola secara baik akan menjadi asset yang sangat berharga bagi pemerintah.

Berdasarkan data dari Dinas Kebudayaan dan Pariwisata Kota Semarang pada tahun 2011-2017. Terjadi peningkatan yang cukup pesat pada kunjungan wisatawan di Kota Semarang. Pada tabel 1 bisa dilihat tahun 2011 terdapat 2.100 .923 wisatawan yang berkunjung ke Semarang terdiri dari 2.073.043 wisatawan domestik dan 27.880 merupakan wisatawan asing. Sedangkan berdasarkan data tahun 2015, jumlah kunjungan wisata meningkat hampir 2 kali lipat dengan jumlah 4.324 .479 wisatawan domestik, 51.880 merupakan wisatawan asing dan total 4.376 .359 wisatawan berkunjung ke Kota Semarang.

Tabel 1. Presentasi Kunjungan Wisata

\begin{tabular}{cccccccc}
\hline \multicolumn{7}{c}{ Kunjungan Wisata } \\
\hline \multicolumn{2}{c}{2011} & \multicolumn{2}{c}{2015} & \multicolumn{2}{c}{2017} & \multicolumn{2}{c}{ Persentase } \\
\hline Domestik & Asing & Domestik & Asing & Domestik & Asing & Domestik & Asing \\
\hline 2.100 .923 & 27.880 & 4.324 .479 & 51.850 & 5.500 .757 & 156.000 & $25,3 \%$ & $45,8 \%$ \\
\hline
\end{tabular}

Sumber: Dinas Kebudayaan dan Pariwisata Kota Semarang, 2018. 


\section{Jurnal Ilmu Sosial Vol. 17 | No. 1 | Edisi Januari - Juni 2018 | Hal.64-76}

Meningkatnya jumlah kunjungan wisatawan sebaiknya diiringi dengan pertumbuhan daya tarik wisata baru yang memiliki nilai jual dan lebih inovatif. Pemerintah perlu mengambil langkah cepat untuk melakukan pengembangan dan pembenahan tempat-tempat ikonik di Kota Semarang. Sebagaimana disampaikan Butler (2006) bahwa perkembangan pariwisata adalah sesuatu yang berkelanjutan, namun pada suatu saat bisa saja terjadi antiklimaks dari perkembangan dan pembangunan pariwisata di suatu destinasi sebab tidak adanya perubahan atau unsur kebaruan. Sehingga terjadi kemerosotan jumlah wisatawan dan kualitas destinasi. Oleh sebab itu, dibutuhkan beberapa rencana terintegrasi yang menghubungkan keunggulan strategi dari pengembangan kawasan dengan tantangan lingkungan.

Kawasan sungai Banjir Kanal Barat (BKB) merupakan salah satu dari sekian banyak Daerah Tujuan Wisata (DTW) di Kota Semarang, yang masuk pada kategori DTW Alam. Wali Kota Semarang Hendrar Prihadi menggagas Banjir Kanal Barat sebagai tempat wisata air berkelas dunia dengan melibatkan masyarakat (www.liputan6.com). Hal ini juga telah tertuang dalam Peraturan Daerah Kota Semarang No.14 Tahun 2011 Tentang Rencana Tata Ruang Wilayah Kota Semarang Tahun 2011-2031, Paragraf 9 Pasal 86 Tentang Kawasan Wisata huruf a disebutkan bahwa pengembangan dan peningkatan wisata bahari di Kecamatan Semarang Utara, Kecamatan Genuk, Kecamatan Semarang Barat, dan Kecamatan Tugu. Artinya, Banjir Kanal Barat termasuk di dalam prioritas menjadi kawasan wisata bahari yang mengandalkan kondisi alam.

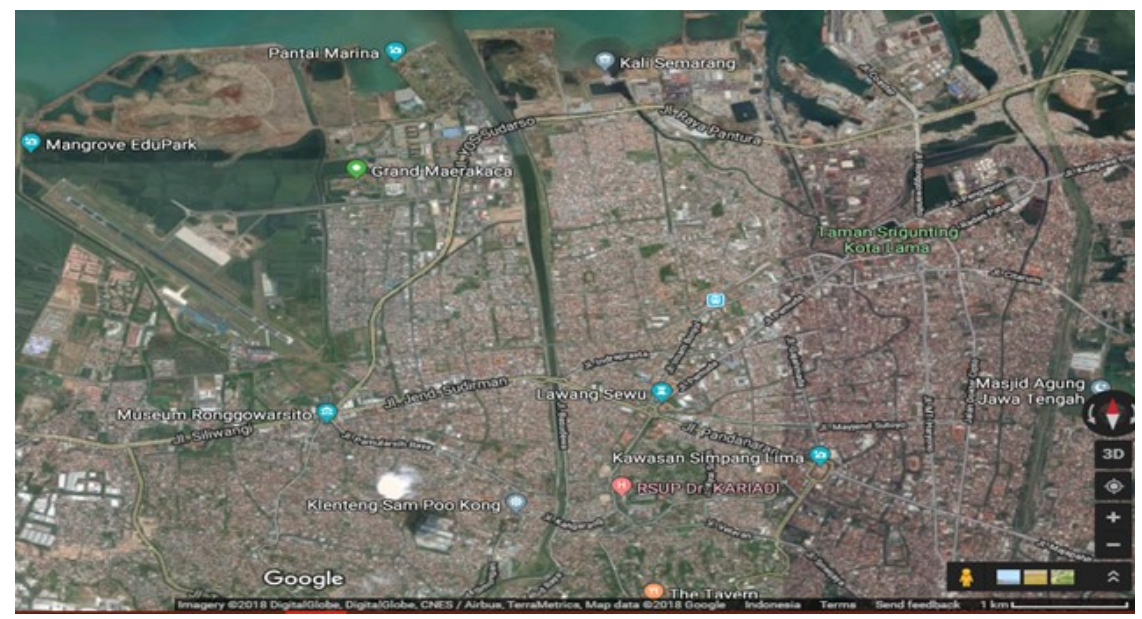

\section{Gambar 1: Lokasi kawasan Banjir Kanal Barat}

Sumber : googlemaps.co.id

Ket: ( --- ) Kecamatan Semarang Barat, ( ----- ) Kawasan BKB

Banjir Kanal Barat seperti pada gambar 1 adalah salah satu sungai besar yang dibangun oleh Belanda untuk mengatasi permasalahan banjir. Kanal barat adalah sebuah 


\section{Jurnal Ilmu Sosial Vol. $17 \mid$ No. 1 | Edisi Januari - Juni 2018 |Hal.64-76}

sungai terpanjang yang ada di Kota Semarang. Dimana kanal ini adalah hilir dari Kali Garang dan Kali Kreo dan Sungai Kripik yang sumber airnya berasal dari Gunung Ungaran. Banjir Kanal Barat memiliki panjang 5,4 km. Pada tahun 2010, pemerintah pusat melalui Kementerian Pekerjaan Umum menerima bantuan dari Japan International Coorporation (JICA) untuk melakukan normalisasi sungai. Dalam perencanaan awal telah ditetapkan pembagian zona (wilayah) kenyamanan sungai dengan menetapkan 7 (tujuh) area, dengan 5 kategori diantaranya: (1) pemukiman dan rekreasi serta tempat bersejarah, (2) kesehatan dan olahraga, (3) wahana air baru semarang, (4) lanskap sungai, keramah tamahan dan pertunjukan, (5) lingkungan sungai dan rekreasi.

Fungsi penetapan zona ini diharapkan mampu menyediakan ruang terbuka/tempat komunikasi bagi masyarakat dan wisatawan. Namun, penelitian terdahulu yang dilakukan oleh Saraswati (2016) mengungkapkan bahwa BKB belum sepenuhnya mampu menjadi daya tarik wisata, hal ini bisa terlihat dari aktifitas yang dilakukan dan kondisi bantaran pada tabel 2, antara lain:

Tabel 2: Aktivitas Di Kawasan Banjir Kanal Barat

\begin{tabular}{cl}
\hline No & \multicolumn{1}{c}{ Aktivitas/Kegiatan Yang Dilakukan } \\
\hline $\mathbf{1}$ & Orang menjaring ikan \\
\hline $\mathbf{2}$ & Jasa penyebrangan dengan perahu sederhana \\
\hline $\mathbf{3}$ & Jual beli kayu bekas \\
\hline $\mathbf{4}$ & Sebagai tempat penyimpanan drum dan barang bekas \\
\hline $\mathbf{5}$ & Mencari ikan di atas perahu \\
\hline $\mathbf{6}$ & Mendirikan warung makan gulai \\
\hline $\mathbf{7}$ & Berdagang perkakas rumah tangga \\
\hline $\mathbf{8}$ & Bermain bola (menjadi lapangan bola) \\
\hline $\mathbf{9}$ & Bercocok tanam di bantaran sungai \\
\hline $\mathbf{1 0}$ & Memelihara ayam di atas jalan setapak \\
\hline $\mathbf{1 1}$ & Fasilitas teribun yang tidak terawatt \\
\hline $\mathbf{1 2}$ & Suasana bantaran yang gelap pada malam hari \\
\hline
\end{tabular}

Sumber: Diolah dari Saraswati (2016)

Data dari penelitian tersebut mengasumsikan bahwa kegiatan masyarakat belum sepenuhnya mengarah pada atraksi wisata guna mendukung BKB sebagai destinasi wisata. Kesadaran masyarakat terhadap kepariwisataan masih minim dan belum menjadikan kehidupan bertumpu pada dunia pariwisata. Usaha pemerintah daerah dalam 


\section{Jurnal Ilmu Sosial Vol. 17 | No. 1 | Edisi Januari - Juni 2018 | Hal.64-76}

mengembangkan BKB sebagai destinasi wisata juga mengalami kendala dalam hal pengelolaannya. Sebab aset BKB merupakan milik pemerintah pusat yang dikelola oleh Balai Besar Wilayah Sungai Pemali Juana Jawa Tengah.

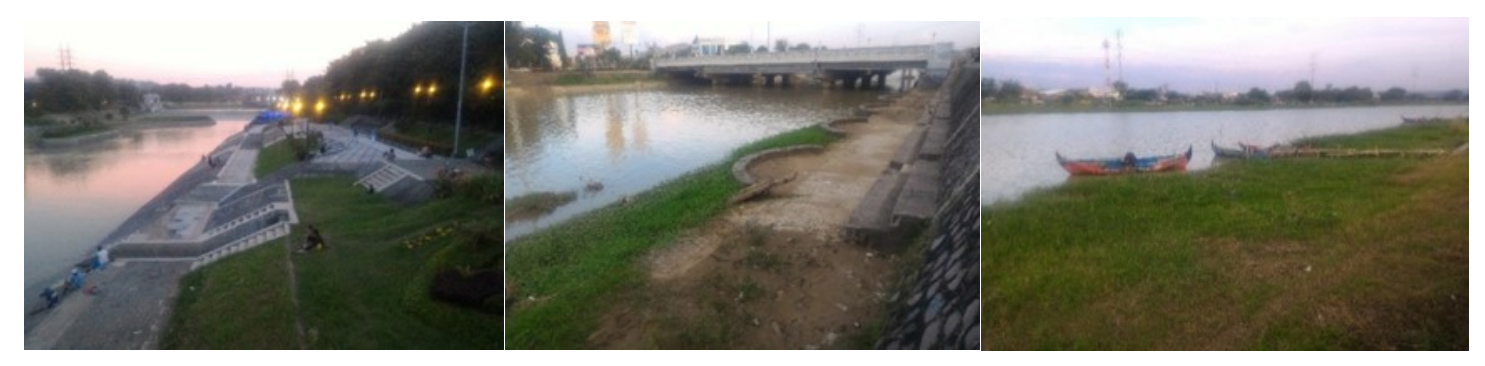

\section{Gambar 2: Kondisi Existing Kawasan Banjir Kanal Barat}

Sumber : Koleksi pribadi penulis diambil pada 28 Maret 2018 jam 16.00 s/d 18.00 wib

Masyarakat menyayangkan fasilitas yang ada di area ini kurang lengkap dan cenderung sempit seperti yang bisa dilihat pada gambar 2. Tidak banyak kegiatan yang bisa dilakukan masyarakat maupun atraksi yang bisa dinikmati pada kawasan tersebut. Pengunjung berharap area wisata "murah" ini dapat dilengkapi dengan fasilitas-fasilitas yang lebih menarik, agar DTW ini lebih dikenal oleh wisatawan dalam maupun dari luar Kota Semarang. Pendapat masyarakat ini juga didukung dari hasil penelitian Supriyono (2017) dengan judul "Estetika Lingkungan Bantaran Sungai Banjir Kanal Barat Semarang”, yang menyimpulkan bahwa diperlukan inovasi agar BKB menjadi lebih menarik dan dapat menjadi daya tarik wisata permanen bukan sekedar penyelenggaraan even musiman.

Menjadi tugas dari pemerintah untuk memenuhi harapan masyarakat, sebagaimana disampaikan beberapa ahli (Wilson, 2010; Dwiyanto, 2009; Kismartini, 2009; Ndraha, 2003) bahwa tugas dari pemerintah adalah melayani masyarakat, mewujudkan keinginan-keinginan dari masyarakat, hal ini diwujudkan melalui kebijakan-kebijakan yang diambilnya, termasuk dalam kebijakan pengembangan wisata.

Bryant dan White (1987) melihat bahwa tugas nyata pemerintah adalah melaksanakan pembangunan melalui berbagai kegiatan dan proyek. Terkait dengan pengembangan kawasan wisata maka agar program dan proyek tersebut sukses maka diperlukan strategi dalam pengembangan pariwisata di kawasan Banjir Kanal Barat. Tujuan dari penelitian ini adalah untuk menganalisis faktor internal dan faktor eksternal dalam rangka mendapatkan strategi bagi pengembangan BKB sebagai kawasan wisata.

\section{a. Strategi Pengembangan Pariwisata}

Menurut Glueck dan Jauch (2004: 1) strategi diartikan sebagai disatukannya 


\section{Jurnal Ilmu Sosial Vol. $17 \mid$ No. 1 | Edisi Januari - Juni 2018 |Hal.64-76}

beberapa rencana, luas dan terintegrasi yang menghubungkan keunggulan strategi dari perusahaan dengan tantangan lingkungan dan yang dirancang untuk memastikan bahwasanya tujuan utama perusahaan dapat dicapai melalui implementasi yang tepat oleh organisasi.

Pengembangan merupakan upaya memperluas atau mewujudkan setiap potensi, membawa pada suatu keadaan secara bertingkat pada suatu keadaan yang lebih lengkap, lebih besar, lebih baik, dan memajukan sesuatu dari yang sederhana kepada yang lebih kompleks (Sudjana, 2000 dalam Ramly, 2007).

Usaha pengembangan pariwisata merupakan usaha untuk mengembangkan industry pariwisata dan usaha pembangunan. Menurut Marpaung (2009), pengembangan kepariwisataan dilandaskan pada usaha sebagi berikut:

1. Menjaga dan membina keindahan alam serta kekayaan didalamnya.

2. Menyediakan fasilitas-fasilitas, transportasi, akomodasi, entertainment, dan pelayanan kepariwisataan.

3. Mengusahakan kelacaran transportasi.

4. Menggerakkan kebijaksanaan perhubungan, agar memudahkan wisatawan hadir.

Dalam pengembangan daya tarik wisata pemerintah harus memiliki strategi yang dapat memanfaatkan sumber daya alam secara terencana dan melibatkan banyak elemen dengan mengidentifikasi secara menyeluruh obyek yang mampu dikembangkan serta infrastruktur yang akan dihadirkan.

\section{b. Analisis SWOT}

Analisis SWOT adalah indentifikasi berbagai faktor secara sistematis untuk merumuskan strategi yang didasarkan pada logika yang dapat memaksimalkan kekuatan (strengths) dan peluang (opportunities), namun secara bersamaan dapat menimbulkan kelemahan (weaknesses) dan ancaman (threat) (Rangkuti, 2000). Melalui analisis ini seperti yang bisa dilihat pada tabel 3 kita dapat mengidentifikasi strategi pengembangan daya tarik wisata. 
Tabel 3: Matriks SWOT

\begin{tabular}{|c|c|c|}
\hline $\begin{array}{l}\text { IFAS (Internal Factor } \\
\\
\text { Analysis } \\
\text { EFAS } \\
\text { (Eksternal } \\
\text { Factor Analysis } \\
\text { Summary) }\end{array}$ & $\begin{array}{l}\text { Kekuatan } \\
\text { (Strenght) } \\
\text { Identifikasi } \\
\text { Permasalahan }\end{array}$ & $\begin{array}{l}\text { Kelemahan } \\
\text { (Weakness) } \\
\text { Identifikasi } \\
\text { Permasalahan }\end{array}$ \\
\hline $\begin{array}{c}\text { Peluang } \\
\text { (Opportunities) } \\
\text { Identifikasi } \\
\text { Permasalahan }\end{array}$ & $\begin{array}{c}\text { Strategi S-O } \\
\text { Upaya menarik keun- } \\
\text { tungan secara kompetitif } \\
\text { dari peluang yang tersedia } \\
\text { dalam lingkungan ekster- } \\
\text { nal (strategi positif) }\end{array}$ & $\begin{array}{c}\text { Strategi W-O } \\
\text { Upaya untuk mengatasi } \\
\text { kelemahan dengan memo- } \\
\text { bilisasi sumber daya guna } \\
\text { meraih peluang }\end{array}$ \\
\hline $\begin{array}{l}\text { Tantangan } \\
\text { (Threat) } \\
\text { Identifikasi } \\
\text { Permasalahan }\end{array}$ & $\begin{array}{c}\text { Strategi S-T } \\
\text { Upaya untuk mengek- } \\
\text { splorasi kekuatan agar } \\
\text { mampu mengatasi an- } \\
\text { caman/kendala/ tantangan }\end{array}$ & $\begin{array}{c}\text { Strategi W-T } \\
\text { Upaya untuk mengatasi } \\
\text { kelemahan dengan memo- } \\
\text { bilisasi sumber daya guna } \\
\text { meraih peluang (strategi } \\
\text { defensive) }\end{array}$ \\
\hline
\end{tabular}

Sumber: Rangkuti, 2000.

\section{METODE PENELITIAN}

Penelitian ini merupakan penelitian deskriptif dengan menggunakan pendekatan kualitatif. Analisa didapat dari lingkungan internal dan eksternal organisasi kemudian dihimpun beberapa variabel internal dan eksternal untuk dijadikan bahan pembahasan. Data yang digunakan dalam penelitian ini data primer yang diperoleh melalui observasi, wawancara, dan dokumentasi yang dilakukan Dinas Kebudayaan dan Pariwisata Kota Semarang, Balai Besar Wilayah Sungai Pemali Juana Jawa Tengah, masyarakat. Sedangkan data sekunder, diperoleh dari Badan Pusat Statistik, Dinas Kebudayaan dan Pariwisata Kota Semarang, Balai Besar Wilayah Sungai (BBWS) Pemali Juana Jawa Tengah.

Batasan penelitian ini adalah pada strategi yang dapat dilakukan bagi pengembangan Banjir Kanal Barat sebagai daya tarik wisata yang menarik untuk dikunjungi bagi wisatawan. Adapun lokasi penelitian pada situs Banjir Kanal Barat di Kota Semarang. Selanjutnya teknis analisis data mengunakan reduksi data, model data (bentuk dari model data lebih bersifat naratif dengan menggunakan matriks SWOT), klasifikasi dan kesimpulan. 


\section{HASIL DAN PEMBAHASAN}

\section{a. Identifikasi Faktor Internal}

\section{a) Kekuatan}

Terdapat beberapa kekuatan dari faktor internal, diantaranya: adanya keinginan dari Walikota Semarang terhadap pengembangan BKB menjadi destinasi wisata baru di kawasan Semarang Barat yang telah diatur dalam Perda Tata Ruang, lalu suksesnya Disbudpar Kota Semarang dalam penyelenggaraan Festival di BKB. Lalu, nuansa alam dan panorama yang indah serta keleluasaan pandangan menjadikan BKB sebagai kawasan yang digemari oleh masyarakat sebab penataan taman di beberapa titik serta desain batu miring yang ada menambah kesan artistik kawasan BKB, sehingga membuat warga ingin berkunjung. Selanjutnya, sumber daya air merupakan kekuatan utama sebab dengan air ada banyak potensi wisata yang bisa disajikan mengingat lokasi yang sangat strategis serta mudah diakses.

\section{b) Kelemahan}

Adapun kelemahan dari faktor internal diantaranya: Pemerintah Kota tidak bisa sepenuhnya mengelola BKB, sebab BKB merupakan aset pemerintah pusat yang dikelola oleh Balai Besar Wilayah Sungai Pemalai Juana. Dalam beberapa tahun BKB hanya mampu menjadi tempat even tahunan, belum mampu menjadi destinasi permanen. Sejak dibangun BKB tidak memiliki fasilitas pendukung bagi wisatawan. Bahkan kondisinya kini cenderung tidak terawat dan kotor. Sehingga, belum menjadi destinasi favorit sebab warga masyarakat yang datang hanya bisa menikmati keindahan alam dan pemadangan tanpa ada atraksi yang bisa dilakukan. Peran masyarakat disekitar kawasan BKB juga tidak dirasakan karena mayoritas masyarakat belum sadar akan potensi wisata yang ada. Untuk fasilitas dan lokasi parkir sangat terbatas dan sempit, sehingga menyulitkan bagi pengendara lain.

\section{b. Identifikasi Faktor Eksternal}

\section{a) Peluang}

Dalam faktor eksternal terdapat beberapa peluang, diantaranya: pemerintah pusat maupun pemerintah provinsi memiliki peran berbeda dalam mengelola $\mathrm{BKB}$, pada intinya dukungan pemerintah sangat besar. Lalu terdapat banyak investor yang tertarik, namun masih terkendala terkait perijinan pamanfaatan lokasi disekitar sungai. Hilir sungai mengarah ke Laut Jawa merupakan peluang sebab hilir sungai juga mampu terkoneksi dengan destinasi wisata maerokoco. Hadirnya masyarakat di sekitar kawasan BKB menjadi potensi baru yang bisa dimanfaatkan untuk menghadirkan produk UMKM. Hal lainnya adalah dibukanya jalan baru menuju akses bandara, menjadikan BKB semakin strategis. Lalu adanya pembangunan bendung gerak akan memudahkan pemanfaatan air untuk berbagai atraksi wisata. 


\section{b) Tantangan}

Adapun yang menjadi tantangan dalam faktor eksternal yaitu: saat hujan deras, kondisi arus sungai deras dan permukaan air sangat tinggi menjadi rawan jika tidak diwasapadai. Selanjutnya, akses yang dimiliki Pemkot sangat terbatas kecuali pada batas sempadan sungai. Hal ini karena aset BKB sepenuhnya milik pemerintah pusat yang di kelola BBWS Pemali Juana. Lalu, pemahamaman masyarakat terhadap konsep sadar wisata masih rendah dan tidak sadar akan peluang baru. Selain itu, disaat musim utara, derasnya ombak dan kencangnya angin serta dalamnya sungai harus diwaspadai. Hal yang memprihatinkan lainnya ialah masih banyak ditemukan masyarakat yang melakukan aktivitas MCK di sungai. Tentu saja hal ini sangat tidak baik bagi sebuah kawasan wisata.

Berdasarkan identifikasi yang dilakukan selanjutnya dilakukan analisis dengan kekuatan (strength), kelemahan (weekness), peluang (opportunies) dan ancaman (threat) yang dilakukan dengan analisis SWOT. Strategi yang dapat dilakukan dalam pengembangan Banjir Kanal Barat sebagai daya tarik wisata sesuai analisis SWOT adalah dengan menghasilkan empat alternatif strategi yaitu alternatif Strategi SO (ciptakan strategi yang mengunakan kekuatan untuk memanfaatkan peluang), alternatif strategi WO (ciptakan strategi yang yang meminimalkan kelemahan untuk memanfaatkan peluang), alternatif strategi ST (ciptakan strategi yang mengunakan kekuatan untuk mengatasi ancaman) dan alternatif strategi WT (ciptakan strategi yang meminimalkan kelemahan-kelemahan dan menghindari ancaman).

Untuk menghasilkan strategi pengembangan bagi BKB menjadi sebuah kawasan yang memiliki daya tarik wisata, maka dilakukan identifikasi faktor-faktor yang mempengaruhi menggunakan matriks analisis SWOT seperti pada tabel 4 .

Tabel 4: Matriks SWOT Pengembangan BKB

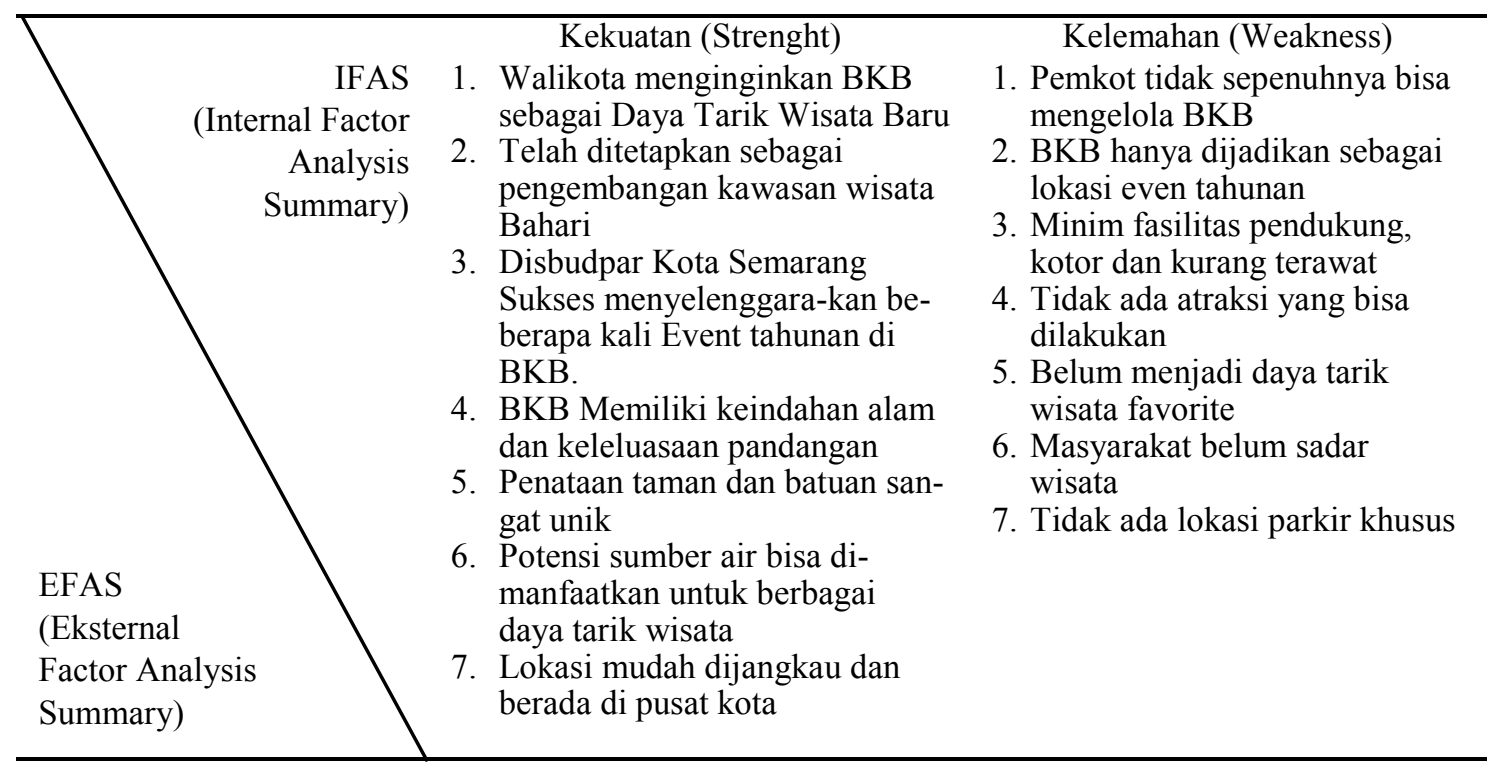


Tabel 4: Matriks SWOT Pengembangan BKB

\begin{tabular}{|c|c|c|}
\hline Peluang (Opportunities) & Strategi SO & Strategi WO \\
\hline $\begin{array}{l}\text { 1. Dukungan pemerintah pusat } \\
\text { dan provinsi terkait pem- } \\
\text { bangunan wilayah sungai } \\
\text { 2. Besarnya potensi pemodal } \\
\text { yang akan berinvestasi di } \\
\text { sekitar wilayah BKB } \\
\text { 3. Hilir sungai mengarah ke } \\
\text { laut jawa } \\
\text { 4. Mampu terkoneksi dengan } \\
\text { kawasan mangrove maero- } \\
\text { koco } \\
\text { 5. Masyarakat bisa mengisi } \\
\text { penyedia jasa wisata, } \\
\text { menjual kuliner dan aneka } \\
\text { souvenir dan produk } \\
\text { UMKM } \\
\text { 6. Potensi sebagai destinasi } \\
\text { favorite karena berdekatan } \\
\text { dengan jalan akses bandara } \\
\text { 7. Adanya pembangunan ben- } \\
\text { dung gerak }\end{array}$ & $\begin{array}{l}\text { 1. Mengundang investor dan } \\
\text { bekerjasama dengan } \\
\text { berbagai pihak. S1, S2, S6, } \\
\text { S7, 02, 04, 07. } \\
\text { 2. Mengikutsertakan masyara- } \\
\text { kat dalam proses } \\
\text { perencanaan, pengemba } \\
\text { ngan serta pengelolaan } \\
\text { BKB. S1, S4, S6, S7, 05, } \\
\text { 07. } \\
\text { Mengembangkan atraksi } \\
\text { wisata khusus bernuansa } \\
\text { air. S2, S4, S6, O3, O6, O7 }\end{array}$ & $\begin{array}{l}\text { 1. Menghadirkan fasilitas- } \\
\text { fasilitas wisata yang dapat } \\
\text { dinikmati oleh masyarakat. } \\
\text { W1, W2, W3, W4, W5, } \\
\text { W7, O4, O6. } \\
\text { 2. Pengembangan kompetensi } \\
\text { SDM sebagai bagian dari } \\
\text { sekor wisata. W3, W4, W5, } \\
\text { W6, O5. } \\
\text { 3elakukan koordinasi } \\
\text { kepada pemerintah pusat, } \\
\text { provinsi serta pihak swasta. } \\
\text { W1, W2, W7, O1, O2, O4, } \\
\text { O7. }\end{array}$ \\
\hline $\begin{array}{l}\text { Tantangan (Threat) } \\
\text { 1. Turunnya air bah dari ka- } \\
\text { wasan semarang atas saat } \\
\text { hujan deras } \\
\text { 2. Terbatasnya akses untuk } \\
\text { memanfaatkan kawasan } \\
\text { BKB } \\
\text { 3. Asset BKB merupakan } \\
\text { milik pemerintah pusat } \\
\text { yang dikelola BBWS Pema- } \\
\text { li Juana } \\
\text { 4. Masyarakat tidak memiliki } \\
\text { konsep tentang sadar wisata } \\
\text { 5. Derasnya ombak dan angin } \\
\text { saat musim utara } \\
\text { 6. Dalamnya sungai dan } \\
\text { kecangnya arus } \\
\text { 7. Masyarakat tempatan masih } \\
\text { melakukan MCK (mandi } \\
\text { cuci kakus) di kawasan } \\
\text { sungai }\end{array}$ & $\begin{array}{l}\text { Strategi S-T } \\
\text { 1. Mengoptimalkan potensi } \\
\text { alam dan keunikan BKB } \\
\text { dengan melakukan pengem- } \\
\text { bangan daya tarik wisata } \\
\text { yang ramah lingkungan. S2, } \\
\text { S4, S5, S6, T1, T7. } \\
\text { 2. Melakukan pemberdayaan, } \\
\text { penyuluhan serta melibat- } \\
\text { kan masyarakat tentang arti } \\
\text { pentingnya sadar wisata dan } \\
\text { mengembangkan daya tarik } \\
\text { wisata. S1, S2, T4, T7 }\end{array}$ & $\begin{array}{l}\text { Strategi W-T } \\
\text { 1. Membentuk kelompok sa- } \\
\text { dar wisata yang akan } \\
\text { mengkorrdinir pengem- } \\
\text { bangan BKB. W1, W2, W5, } \\
\text { W6, W7, T2, T3, T4. } \\
\text { 2. Menjadikan BKB sebagai } \\
\text { kawasan wisata air kreatif } \\
\text { dan inovatif. W2, W3, W4, } \\
\text { W5, T1, T5, T6. }\end{array}$ \\
\hline
\end{tabular}

Selanjutnya berdasarkan penilaian faktor internal dan eksternal di atas, kemudian dilakukan identifikasi penyusunan strategi. Hal ini bertujuan guna mendapatkan arahan dalam pengembangan BKB sebagai daya tarik wisata dengan mempertimbangkan dan menggabungkan masing-masing faktor yang merupakan kekuatan, kelemahan, peluang dan ancaman dalam matriks analisis SWOT seperti pada tabel 5. 


\section{Tabel 5: Perangkingan Strategi}

\begin{tabular}{|c|c|c|c|c|}
\hline No. & $\begin{array}{l}\text { Alternatif } \\
\text { Pilihan }\end{array}$ & Faktor Terkait & Bobot & Prioritas \\
\hline \multirow[t]{3}{*}{$\begin{array}{l}\text { Strategi } \\
\text { SO }\end{array}$} & $\begin{array}{l}\text { 1. Mengundang investor dan beker- } \\
\text { jasama dengan berbagai pihak }\end{array}$ & $\begin{array}{l}\mathrm{S} 1, \mathrm{~S} 2, \mathrm{~S} 6, \mathrm{~S} 7, \\
\mathrm{O} 2, \mathrm{O} 4, \mathrm{O} 7\end{array}$ & 1.996 & III \\
\hline & $\begin{array}{l}\text { 2. Mengikutsertakan masyarakat } \\
\text { dalam proses perencanaan, } \\
\text { pengembangan serta pengelolaan } \\
\text { BKB }\end{array}$ & $\begin{array}{l}\text { S1, S4, S6, S7, } \\
\text { O5, O7 }\end{array}$ & 1.796 & IV \\
\hline & $\begin{array}{l}\text { 3. Mengembangkan atraksi wisata } \\
\text { khusus bernuansa air }\end{array}$ & $\begin{array}{l}\mathrm{S} 2, \mathrm{~S} 4, \mathrm{~S} 6, \mathrm{O} 3, \\
\mathrm{O} 6, \mathrm{O} 7\end{array}$ & 2.039 & II \\
\hline \multirow[t]{2}{*}{$\begin{array}{l}\text { Strategi } \\
\text { ST }\end{array}$} & $\begin{array}{l}\text { 1. Mengoptimalkan potensi alam } \\
\text { dan keunikan BKB dengan } \\
\text { melakukan pengembangan daya } \\
\text { tarik wisata yang ramah ling- } \\
\text { kungan }\end{array}$ & $\begin{array}{l}\text { S2, S4, S5, S6, } \\
\text { T1, T7 }\end{array}$ & 1.736 & $\overline{\mathrm{VI}}$ \\
\hline & $\begin{array}{l}\text { 2. Melakukan pemberdayaan, } \\
\text { penyuluhan serta melibatkan } \\
\text { masyarakat tentang arti pent- } \\
\text { ingnya sadar wisata dan mengem- } \\
\text { bangkan daya tarik wisata }\end{array}$ & $\mathrm{S} 1, \mathrm{~S} 2, \mathrm{~T} 4, \mathrm{~T} 7$ & 1.099 & $X$ \\
\hline \multirow[t]{3}{*}{$\begin{array}{l}\text { Strategi } \\
\text { WO }\end{array}$} & $\begin{array}{l}\text { 1. Menghadirkan fasilitas-fasilitas } \\
\text { wisata yang dapat dinikmati oleh } \\
\text { masyarakat }\end{array}$ & 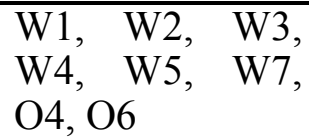 & 2.175 & $\overline{\mathrm{I}}$ \\
\hline & $\begin{array}{l}\text { 2. Pengembangan kompetensi SDM } \\
\text { sebagai bagian dari sekor wisata }\end{array}$ & $\begin{array}{l}\text { W3, W4, W5, } \\
\text { W6, O5 }\end{array}$ & 1.323 & IX \\
\hline & $\begin{array}{l}\text { 3. Melakukan koordinasi kepada } \\
\text { pemerintah pusat, provinsi serta } \\
\text { pihak swasta }\end{array}$ & $\begin{array}{l}\text { W1, W2, W7, } \\
\text { O1, O2, O4, O7 }\end{array}$ & 1.632 & VII \\
\hline \multirow[t]{2}{*}{$\begin{array}{l}\text { Strategi } \\
\text { WT }\end{array}$} & $\begin{array}{l}\text { 1. Membentuk kelompok sadar } \\
\text { wisata yang akan mengkorrdinir } \\
\text { pengembangan BKB }\end{array}$ & $\begin{array}{l}\text { W1, W2, W5, } \\
\text { W6, W7, T2, T3, } \\
\text { T4 }\end{array}$ & 1.785 & $\overline{\mathrm{V}}$ \\
\hline & $\begin{array}{l}\text { 2. Menjadikan BKB sebagai kawa- } \\
\text { san wisata air kreatif dan inovatif }\end{array}$ & $\begin{array}{l}\text { W2, W3, W4, } \\
\text { W5, T1, T5, T6 }\end{array}$ & 1.603 & VIII \\
\hline
\end{tabular}

\section{KESIMPULAN}

Faktor-faktor internal yang mendukung pengembangan Banjir Kanal Barat sebagai destinasi wisata adalah adanya dukungan Walikota, penetapan kawasan, pernah diadakan event besar, kawasan yang unik yang identik dengan air, lokasi mudah dijangkau. Sementara, yang menghambat adalah, persoalan kewenangan, event hanya diadakan musiman, minimnya fasilitas, tidak ada atraksi dan daya tarik, kesadaran masyarakat rendah, dan minimnya lokasi parkir.

Faktor-faktor eksternal yang mendukung pengembangan BKB sebagai destinasi wisata adalah dukungan stakholders, kehadiran investor, lokasi menuju laut dan kawasan maerokoco serta berdekatan dengan jalan akses bandara, partisipasi masyarakat, serta adanya 


\section{Jurnal Ilmu Sosial Vol. 17 | No. 1 | Edisi Januari - Juni 2018 | Hal.64-76}

bendung gerak. Sementara yang menghambat adalah terbatasnya kewenangan mengelola situs $\mathrm{BKB}$, kondisi air, kedalaman, masyarakat tidak sadar wisata dan lingkungan kotor.

Berdasarkan analisis yang telah dilakukan, maka strategi pengembangan Banjir Kanal Barat dapat dilakukan dengan cara: (1) menghadirkan fasilitas-fasilitas wisata yang dapat dinikmati oleh masyarakat, (2) mengembangkan atraksi wisata khusus bernuansa air, (3) mengundang investor dan bekerjasama dengan berbagai pihak, (4) mengikutsertakan masyarakat dalam proses perencanaan, pengembangan serta pengelolaan BKB, (5) membentuk kelompok sadar wisata yang akan mengkordinir pengembangan BKB, (6) mengikutsertakan masyarakat dalam proses perencanaan, pengembangan serta pengelolaan BKB, (7) melakukan koordinasi kepada pemerintah pusat, provinsi serta pihak swasta, (8) menjadikan BKB sebagai kawasan wisata air kreatif dan inovatif, (9) pengembangan kompetensi SDM sebagai bagian dari sektor wisata, (10) melakukan pemberdayaan, penyuluhan serta melibatkan masyarakat tentang arti pentingnya sadar wisata dan mengembangkan daya tarik wisata.

\section{SARAN}

1. Pemerintah daerah agar lebih jeli dalam memanfaatkan segala potensi yang ada di daerah serta intens berkoordinasi kepada BBWS sebagai pengelola BKB untuk mempermudah pengembangan yang akan dilakukan.

2. Pengembangan daya tarik wisata BKB harus dilakukan secara berkelanjutan, dengan melengkapi berbagai fasilitas pendukung untuk menambah daya tarik bagi wisatawan, sehingga tidak terjadi stagnasi terhadap daya tarik wisata.

\section{DAFTAR PUSTAKA}

Banjir Kanal Barat Semarang Bakal Jadi Objek Wisata Dunia. https://www.liputan6.com/ regional/read/3237004/banjir-kanal-barat-semarang-bakal-jadi-objek-wisata-dunia. Diakses 8 April 2018.

Bryant, Coralie dan Louis G. White. 1987. Manajemen Pembangunan untuk Negara Berkembang. Jakarta : LP3ES.

Butler, R. W, (2006). The Tourism Area Life Cycle: Application and Modification, Channel View Publication, Clevedon UK.

Fatimah, Siti. (2015). Strategi Pengembangan Obyek Dayat Tarik Wisata Religi. Universitas Islam Negeri Wali Songo. Semarang. 


\section{Jurnal Ilmu Sosial Vol. $17 \mid$ No. 1 | Edisi Januari - Juni 2018 |Hal.64-76}

Glueck, William F and Jauch Laurance R., (2000). Bussiness Policy and Strategic Management, and Integrated Approach. Houghton Miflin Company: USA.

Indiahono, Dwiyanto. 2009. Kebijakan Publik (Berbasis Dynamic Policy Analysis). Yogyakarta: Gava Media

Keban T, Yeremias. (2004). Enam Dimensi Strategis, Administrasi Publik, Konsep, Teori dan Isu. Yogyakarta: Gava Media.

Kompas, 3 Oktober 2013

Kismartini dkk. 2009. Analisis Kebijakan Publik. Universitas Terbuka. Jakarta.

Marpaung, Happy. (2002). Pengetahuan Kepariwisataan. Alfabeta: Bandung.

Ndraha, Taliziduhu. 2003. Kybernologi (Ilmu Pemerintahan Baru). Jilid 1-2. Rineka Cipta. Jakarta.

Ramly, N. (2007). Pariwisata Berwawasan Lingkungan. Penerbit Grafindo Khazanah Ilmu. Jakarta

Rangkuti, F. (2000). Analisis SWOT: Teknik Membedah Kasus Bisnis-Reorientasi Konsep Perencanaan Strategi Untuk Menghadapi Abad 21. PT Gramedia Utama, Jakarta.

Saraswati, Dian Ratih, et.al. (2016). Pemanfaatan Ruang Terbuka Publik pada Bantaran Sungai Banjir Kanal Barat Semarang. Prosiding Temu Ilmiah IPLBI, 2016.

Sunaryo, B. (2013). Kebijakan Pembangunan Destinasi Pariwisata: Konsep Dan Aplikasinya Di Indonesia. Yogyakarta: Gava Media.

Supriyono., Kiswari, Nestri MD, (2017). Estetika Lingkungan Bantaran Sungai Banjir Kanal Barat Semarang, Prosiding Temu Ilmiah IPLBI, 2017.

Undang - Undang No. 10 Tahun 2009 Tentang Kepariwisataan.

https://travel.kompas.com/read/2013/10/03/1053467/Semarang.Jejak.Little.Netherland. Diakses 27 Maret 2018.

Wilson, Wodrow. 2010. The Study of Administration. The Academic of Political Science. http://www.jstor.org/stable/2139277 . 